\title{
Does maternal environmental condition during reproductive development induce genotypic selection in Picea abies?
}

\author{
Guillaume BESNARD ${ }^{1,2 *}$, Virginie ACHERÉ ${ }^{2}$, Sylvain JEANDROZ ${ }^{2}, \varnothing_{\text {ystein JOHNSEN }}^{3}$, Patricia FAIVRE \\ RAMPANT $^{2}$, Rüdiger BAUMANN ${ }^{4}$, Gerhard MÜLLER-STARCK ${ }^{4}$, Torre SKRøPPA ${ }^{3}$, Jean-Michel FAVRE ${ }^{2}$ \\ ${ }^{1}$ UNIL, Biophore, Department of Ecology and Evolution, 1015 Lausanne, Switzerland \\ ${ }^{2}$ UMR INRA/UHP 1136 “Tree-Microbe Interactions”, Université H. Poincaré Nancy I, Faculté des Sciences, \\ BP 239, 54506 Vandœuvre-Lès-Nancy, France \\ ${ }^{3}$ Norwegian Forest and Landscape Institute, PO Box 115, 1431 As, Norway \\ ${ }^{4}$ Technische Universität München, Weihenstephan Center of Life and Food Sciences, Section of Forest Genetics, \\ Am Hochanger 13, 85354 Freising, Germany
}

(Received 6 January 2007; accepted 17 August 2007)

\begin{abstract}
In forest trees, environmental conditions during reproduction can greatly influence progeny performance. This phenomenon probably results from adaptive phenotypic plasticity but also may be associated with genotypic selection. In order to determine whether selective effects during the reproduction are environment specific, single pair-crosses of Norway spruce were studied in two contrasted maternal environments (warm and cold conditions). One family expressed large and the other small phenotypic differences between these crossing environments. The inheritance of genetic polymorphism was analysed at the seed stage. Four parental genetic maps covering 66 to $78 \%$ of the genome were constructed using 190 to 200 loci. After correcting for multiple testing, there is no evidence of locus under strong and repeatable selection. The maternal environment could thus only induce limited genotypic-selection effects during reproductive steps, and performance of progenies may be mainly affected by a long-lasting epigenetic memory regulated by temperature and photoperiod prevailing during seed production.
\end{abstract}

adaptability / segregation distortion / parental effect / Picea abies / post-zygotic selection

Résumé - L'environnement maternel induit-il une sélection génotypique durant les différents stades de reproduction chez Picea abies ? Chez les arbres forestiers, les conditions environnementales durant la reproduction peuvent influencer les performances des descendants. Ce phénomène reflète probablement la plasticité phénotypique, mais également il pourrait être associé à une sélection génotypique. Afin de déterminer si des effets sélectifs durant la reproduction sont spécifiques d'un environnement donné, deux familles d'épicéa commun non apparentées ont été obtenues par croisements dirigés dans deux environnements maternels contrastés (conditions chaude et froide). La première famille exprimait de larges différences phénotypiques entre les deux environnements tandis que la seconde ne montrait pas de différence significative. La transmission des polymorphismes génétiques a été étudiée au stade de la graine. Quatre cartes génétiques parentales couvrant 66 à $78 \%$ du génome ont été construites. Aucun effet de sélection n'a été mis en évidence aux différents locus étudiés. L'environnement maternel n'induirait donc que des effets de sélection génotypique relativement faibles durant les stades de la reproduction. Les performances des descendants seraient principalement affectées par une mémoire épigénétique durable régulée par la température et la photopériode régnant durant la production des graines.

adaptabilité / distorsion de ségrégation / effet parental / Picea abies / sélection post-zygotique

\section{INTRODUCTION}

Rapid climatic changes are expected in the next decades and their impact on biodiversity is still an open question $[3,24]$. Understanding mechanisms involved in organism response to environmental variations is an important issue particularly for the conservation of ecosystems or for the genetic resources management of particular species. The process of adaptation to new environments could be relatively prolonged in long-lived species, such as forest trees $[6,16,40]$. A number of examples however indicate that organisms are capable of "rapid" adaptive evolution on contemporary timescales when they face sudden changes in their environment. Such examples

* Corresponding author: gbesnard@unil.ch of contemporary evolution in natural populations can be found among exotic species that frequently encounter different environmental conditions in their introduced range (see [29] for an illustrative example in plants). This is also the case of forest trees. Indeed, these species generally show well-marked local adaptations that often find their expression in heritable traits as cold hardiness or bud set sensitivity to photoperiod (e.g. [10, $19,23])$. Yet, in such long-lived organisms with late reproductive maturity, the number of generations that occurred during the post-glacial expansion that followed the preboreal period (around 10000 to 9000 BP in Europe) does probably not exceed one hundred [26].

The most striking example of tree adaptation to sudden environmental changes is probably that described in Norway 
spruce (Picea abies (L.) Karst.) by Skrøppa and Kohmann [48], and confirmed with independent tests by Tollefsrud et al. (submitted). Under controlled conditions, Norway spruce seedlings which originate from the first generation stands of a German accession (Harz) established in Norway behave almost as the local Norwegian and not as the original German provenances for bud set. In this case, acclimation of introduced material to the local climatic conditions occurred after only one generation. Several other studies clearly indicated an influence of the crossing environment on the performances of different spruce progenies (e.g. [20-22,55]). This rapid change in behaviour may be explained by different factors and, in particular, the occurrence of selective effects during the reproductive process could be one of them. It is commonly accepted that selection during reproductive phases leads to genetic distortions, e.g. allele segregation significantly different from the expected Mendelian inheritance. Such distortions are thought to have a great evolutionary importance $[4,50]$ since they would influence the inheritance of genes involved in adaptive traits. Selection can occur at different stages of the reproductive cycle: during fertilisation (e.g. due to competition between gametes; [34]), early embryogenesis (zygote, proembryo and early embryo viability; [31]) but also during the relatively long haploid phase (e.g. meiosis of pollen and megaspore mother cells, pollen and female gametophyte development) [28,31].

It has also been hypothesised that parental effects (particularly due to genomic imprinting, a process leading to gene transcription variation) could result in a trans-generational adaptive plasticity favouring rapid responses to environmental changes or a better local adaptation (e.g. [2, 12, 27, 33, 38]). Elucidating these adaptive mechanisms would be of great interest for ecological and evolutionary purposes [38] and would also lead to practical applications in seed-orchards [31] and more generally tree breeding.

In order to determine whether selective effects during reproduction are environment specific, we genetically characterized Picea abies full-sib progenies issued from crosses carried out between the same parental genotypes but in different temperature regimes. Our objectives were (i) to detect and locate genomic regions affected by genetic distortion, (ii) to find a possible connection between the distortions and crossing environment, and (iii) to determine whether distortion could be correlated with phenotypic difference caused by the maternal environment. For these purposes, we followed the inheritance of mapped genetic markers (i.e. SSR, SAMPL, ESTP and AFLP) in two families.

\section{MATERIAL AND METHODS}

\subsection{Plant material}

The Norway spruce reproductive cycle is well described by Owens and Blake [30] and Owens et al. [31]. Flower buds are initiated in year $n$ and flowering and seed production is completed during year $n+1$. The various stages of pre-zygotic and post-zygotic stages in year $n+1$ are closely related to the number of degree days (dd) defined as the sum of daily mean temperatures above $5{ }^{\circ} \mathrm{C}$ in a given time period [39]. Syngamy (the fusion of male and female gametes) is
Table I. Freezing injury in autumn on progenies of crosses I and II (data from Johnsen et al. [20,22]). A statistical test of difference between indoor and outdoor full sibs is given for each cross. Needle injury was assessed and analysed as previously described [22]. For more details on crossing procedures see Johnsen et al. [20,22].

\begin{tabular}{lccc}
\hline Cross $\left(\$ \times \sigma^{\prime \prime}\right)$ & $\begin{array}{c}\text { Crossing year, environment } \\
\text { and reference number }\end{array}$ & $\begin{array}{c}\text { Needle } \\
\text { injury }(\%)\end{array}$ & $p$-value* \\
\hline I: $2735 \times$ F2014 & $\begin{array}{c}\text { 1993, Indoor (15046) } \\
\text { 1993, Outdoor (15044) }\end{array}$ & 55 & $<0.0001$ \\
& & & \\
II: $2736 \times 1957$ & 1998, Indoor (15887) & 58 & 0.297 \\
& 1998, Outdoor (1589) & 53 & \\
\hline
\end{tabular}

* Variance analysis, normal $F$-test, assuming families as fixed.

completed at 450-500 dd in Norway spruce [31,39], and proembryo formation takes place when the heat sum approximates 500-550 dd after pollination.

Based on years of experimentation with Norwegian Picea abies accessions [20,22], we were able to identify two full-sib families, which behaved differently according to the temperature experienced by the mother clone during reproductive events (Tab. I). The family from cross I (2735 × F2014; \# 15046 and 15044) expressed large differences in autumn frost hardiness, the cold maternal environment (\# 15044) producing the hardiest full-siblings (Tab. I). The other family (cross II: $2736 \times 1957$, \# 15887 and 15890) expressed small and non-significant difference between the cold and warm conditions (Tab. I). Parental clones ${ }^{1}$ were grown as potted grafts [31], and crosses were performed as previously described either in a greenhouse (warm environment) or outdoor (cold) [20,22,31]. In the greenhouse, the temperatures (\# 15046 and 15887) varied between 20$30{ }^{\circ} \mathrm{C}$ during day and $18-20{ }^{\circ} \mathrm{C}$ during night $(6 \mathrm{~h})$. This warm environment resulted in an accumulation of 1874 and $1841 \mathrm{dd}$ from female meiosis to mature seeds whilst the cold outside conditions (\# 15044 and 15890) accumulated 1171 and 1147 dd in cross I and cross II, respectively [22]. This difference is comparable to an increase of approximately $4{ }^{\circ} \mathrm{C}$ in daily mean temperature during the spring, summer and early autumn. These indoor conditions therefore approximate the temperature rise expected in 100 years [40]. Since we know that progeny performance is not affected by photoperiod and temperature during microsporogenesis [20], fresh pollen of each father clone was collected from a single graft grown indoor. One hundred and thirty seven seeds were genotyped in cross I (79 progenies from warm condition and 58 from cold condition). In cross II, 147 seeds were genotyped (75 and 72 in warm and cold conditions, respectively).

\subsection{DNA preparation and genetic characterisation}

Seeds were germinated on filter paper in Petri dishes according to ISTA rules. After isolation of embryos and megagametophytes under a stereo-microscope, DNA was extracted from both materials using a CTAB method and stored in $1 \mathrm{X}$ TE buffer at $-20^{\circ} \mathrm{C}$ [14]. To avoid selection due to differences in seed viability, embryos of nongerminated seeds were also collected. DNA from the parents was isolated from needles using the same procedure. Parents and progenies from cross I and cross II were then characterised using different marker types to obtain optimal genome coverage [1,47].

\footnotetext{
${ }^{1}$ Genetic maps of the four parents used in cross I and cross II are only available as Annex in electronic form at http://www.afs-journal.org.
} 
To reveal Simple Sequence Repeat (SSR or microsatellite) polymorphism, forty-six primer pairs developed from genomic DNA of Picea species were used [17, 36, 37, 45, 46]. Twentythree additional primer pairs designed in Expressed Sequence Tags (EST) from Picea, Larix and Pinus were used to amplify polymorphic gene regions [5, 8, 35, 42-44,51,52]. Protocols for PCRamplification and polymorphism analysis are given on the web-site http://www.demandt.de/adaptability/pub/microsatellites_database.pdf. Using the SSR technology, complex multi-loci profiles were frequently generated (e.g. with PAAC13, EATC1F7B, EAC6E2, EAC7B9, SpAC1E8 and EAC7F6 primers; see also [30]). Dominant segregating bands generated with this technique were noted as Selective Amplification of Microsatellite Loci (SAMPL; [30]). Furthermore, we designed two new primers from the cDNA accession AJ131106 (PAAC13) previously used by Scotti et al. [44]. PCR amplification from this new primer pair PAAC13GB-for ( ${ }^{\prime}$ 'TCTCTATTGTGGAAATTCACG ${ }^{3}$ ) $)$ PAAC13GB-rev ( ${ }^{\prime}$ ' AACTTGTGGTTGCACGGTTG $^{3}$ ') was performed using the general conditions described in Besnard et al. [5], at an annealing temperature of $52{ }^{\circ} \mathrm{C}$ in a mix containing $2.5 \mathrm{mM} \mathrm{MgCl}_{2}$. We thus obtained a multi-loci profile partially different from that scored by using the PAAC13 primers defined by Scotti et al. [44].

Polymorphism analysis at EST loci frequently needed specific investigation. At EST loci SB06, SB42, Pp.INR.AS01C7, PtlFG.739 and PtlFG.9076, segregating polymorphisms leading to heteroduplex formation were revealed when PCR products were electrophoresed in $8 \%$ acrylamide gels. Polymorphism at EST loci PA0002, PA0038 and SB29 was revealed after digestion of the PCR products with the restriction enzymes HaeIII, HinfI and NdeII, respectively, and electrophoresis in $2 \%$ agarose gels.

When parents displayed the same heterozygous genotype at one locus (i.e. $\mathrm{AB} \times \mathrm{AB}$ ), the megagametophytes were genotyped complementarily to the embryos in order to elucidate each parental contribution to the progeny. Ten loci in cross I [SpAC03, SpAGC1, SpAGC2, pgGB5, SB28, SB29, EAC7B9 (locus A), EAC2B2, EATC1F7B (locus C), UAPgCA91], and six loci in cross II [PA0038, PA0066, SpAG2 (locus B), PGL14 (locus B), UAPgAG150A, UAPsTG25)] were then characterised on both embryos and megagametophytes.

Lastly, to facilitate the linkage mapping of the identified polymorphic SSR, EST and SAMPL markers, we generated anonymous AFLP markers (Amplified Fragment Length Polymorphism) on progenies. A sub-sample of 50 individuals of each crossing-environment progeny was characterised with this technique. Six AFLP primer combinations (a41 to a46) were chosen for the clarity of their electrophoretic profiles and the high level of polymorphism revealed [1]. Electrophoresis of PCR products was carried out on an automated sequencer DNA analyser GeneReadIR 4200 (LiCor) following the experimental protocols described in Acheré et al. [1].

\subsection{Analysis of allele segregation and genotypic class frequencies}

Three types of allele segregation were observed: 1:1 for dominant loci heterozygous in one parent and homozygous or null in the other (simplex markers), 3:1 for dominant loci heterozygous in both parents (duplex markers), and 1:1:1:1 for codominant multiallelic loci (simplex markers common to each parent). A genotype data matrix was constructed for each progeny. For each marker, deviations from the expected Mendelian ratios were detected using a chi-square test
$(P<0.05)$. To reduce the number of false-positives, a Bonferronicorrected chi-square $\left(P<\alpha_{\text {Bonf }}, \alpha_{\text {Bonf }}=0.05 / n\right.$, where $n$ is the number of tests performed (number of distinct loci)) was used [49]. Parental locus-segregation was independently considered in the two crossing environments. To test if the environment affected the inheritance of loci, their segregation was compared between the two maternal environments using a chi-square test. A Bonferroni-corrected chi-square was also used as previously described.

We also analysed pairwise associations of male and female alleles at co-dominant markers for 54 and 51 different loci in cross I and cross II, respectively. This analysis may detect possible selective effects occurring during fertilisation or the early diploid phase at a single locus. For a given locus with parental alleles AB (female) and $\mathrm{ab}$ (male), four genotypic classes (namely $\mathrm{Aa}, \mathrm{Ab}, \mathrm{Ba}$ and $\mathrm{Bb}$ ) will be observed in the progeny. Significant distortions $(P<0.05)$ in the observed frequencies of each genotypic class were revealed by using a chi-square test. A Bonferroni-corrected chi-square was used as previously described to reduce the number of false-positives. A chi-square test was also applied to test for difference in genotypic constitution of progenies issued from the two maternal environments.

\subsection{Genetic map construction}

Construction of parental genetic maps was performed using the pseudo-test cross strategy [13]. Linkage analysis was carried out using JOINMAP version 3.0 [53]. A minimal LOD of 4.0 and a maximum recombination fraction $(\theta)$ of 0.3 were considered as grouping criterions. Recombination rates were converted to genetic distances in centiMorgans (cM) using the Kosambi's mapping function [25]. The male and female parental maps were built up based on both simplex and duplex markers. Both indoor and outdoor populations issued from the same cross were pooled (137 and 147 individuals for cross I and cross II, respectively).

The genome length $(G)$ was estimated for the four parents by using the formula $G=N(N-1) X / K[9,18]$ where $N$ is the number of markers in the final framework map (without ancillary markers), $X$ is calculated as $X=-1 / 2 \ln (1-2 \theta)$ and $K$ is the number of pairs of markers linked at less than $34.7 \mathrm{cM}$. Only simplex markers were used for this estimation using a minimal LOD of 4.0 and a maximum recombination fraction of 0.3 . Additionally, we tested whether markers were randomly distributed using a Poisson distribution function $P(x)=\mathrm{e}^{-\mu} \mu^{x} / x$ !, where $x$ is the number of markers per $10 \mathrm{cM}$ interval and $\mu$ the average marker density in a map [56]. The number of markers in each $10 \mathrm{cM}$ interval was counted and the frequency of each class compared to the expected binomial frequencies by a chisquare test.

The parental maps and the consensus map published by Acheré et al. [1] were compared. Map alignment was carried out by using SSR and ESTP anchor points (co-dominant markers) common to the parental and consensus maps. In addition, AFLP markers segregating 3:1 (duplex loci) allowed us generating bridges between the parental maps of a same cross (e.g. [1]). Lastly, common AFLPs and SAMPLs (according to size homology), mapped independently in the two crosses, were also used to generate inter-cross markers.

\section{RESULTS AND DISCUSSION}

\subsection{Genetic mapping and genome representativeness of marker sampling}

One hundred ninety to 200 segregating markers per parent were obtained in both crosses (Tab. II). Most of these 
Table II. Description of genetic data and parental maps of each parent (see Supplementary material online): numbers of dominant simplex, co-dominant and dominant duplex markers, number of linkage groups, size of each map in cM, number of common markers at least present on two parental maps and number of unlinked markers with unknown position.

\begin{tabular}{|c|c|c|c|c|}
\hline & 2735 (Female, cross I) & F2014 (Male, cross I) & 2736 (Female, cross II) & 1957 (Male, cross II) \\
\hline Number of dominant simplex loci (1:1) & $105(96)^{\mathrm{a}}$ & $103(95)^{\mathrm{a}}$ & $118(108)^{\mathrm{a}}$ & $113(106)^{\mathrm{a}}$ \\
\hline Number of co-dominant loci $(1: 1: 1: 1)$ & $57(54)^{\mathrm{a}}$ & $57(54)^{\mathrm{a}}$ & $51(51)^{\mathrm{a}}$ & $51(51)^{\mathrm{a}}$ \\
\hline Number of dominant duplex loci $(3: 1)$ & 30 & 30 & 31 & 31 \\
\hline Number of linkage groups & 20 & 20 & 16 & 26 \\
\hline Genetic map size (in cM) & 1420 & 1535 & 1443 & 1378 \\
\hline Markers located on at least two maps & 99 & 108 & 105 & 102 \\
\hline Unlinked markers with unknown position & 5 duplex & 1 simplex, 5 duplex & 2 simplex, 4 duplex & 8 simplex, 4 duplex \\
\hline
\end{tabular}

a The number of distinct loci is given in brackets.

Table III. Number of simplex loci (including co-dominant markers) deviating from the expected Mendelian inheritance at $P<0.05$ (when no Bonferroni correction is applied) in both conditions, in indoor condition and outdoor condition. The number of loci differently inherited between the two crossing environments is also given.

\begin{tabular}{|c|c|c|c|c|}
\hline Crossing maternal environment & 2735 (Female, cross I) & F2014 (Male, cross I) & 2736 (Female, cross II) & 1957 (Male, cross II) \\
\hline Indoor + outdoor conditions & $10(6.7 \%)$ & $9(6 \%)$ & $6(3.8 \%)$ & $6(3.8 \%)$ \\
\hline Indoor condition & $3(2 \%)$ & $9(6 \%)$ & $8(5 \%)$ & $6(3.8 \%)$ \\
\hline Outdoor condition & $6(4 \%)$ & $1(0.7 \%)$ & $3(1.9 \%)$ & $2(1.3 \%)$ \\
\hline Between the two crossing environments & $2(1.3 \%)$ & $3(2 \%)$ & $4(2.5 \%)$ & $9(5.7 \%)$ \\
\hline
\end{tabular}

loci $(84 \%)$ corresponded to simplex or codominant markers (segregating $1: 1$ or $1: 1: 1: 1$ ). Based on these genetic data, four parental maps including 16 to 26 linkage groups were constructed (Tab. II; see Supplementary Material). The expected total genome $(G)$ size of each parent was estimated to be $3197 \mathrm{cM}$ for $2735,3103 \mathrm{cM}$ for F2014, $2657 \mathrm{cM}$ for 2736 and $3443 \mathrm{cM}$ for 1957, and the total length of parental maps (Tab. II) represented between 40\% (1957) and 54.3\% (2736) of the genome. These results are in good accordance with the $2839 \mathrm{cM}$ of the map previously published by Paglia et al. [32]. The probability that a new marker added at the map would be linked to another marker present in the framework map was also estimated. The total length of the framework map was reconsidered by adding $34.7 \mathrm{cM}$ (independence distance for a recombination fraction $\theta$ using the Kosambi function) at the end of each linkage group and each isolated marker. Based on these estimations, the present marker sets covered $66.1 \%, 74.1 \%$, $77.8 \%$ and $75.2 \%$ of the genome for 2735, F2014, 2736 and 1957, respectively. More details on genetic maps (i.e. marker distribution, order of common markers) are given in Supplementary Material.

\subsection{Segregation analyses and selection}

We detected between $3.8 \%$ (2736 and 1957) and 6.7\% (2735) of the loci which deviated from the expected Mendelian inheritance at $P<0.05$ (Tab. III). In addition, when marker inheritance was analysed independently in each maternal environment, we detected between $0.7 \%$ (F2014, outdoor) and $6 \%$ (F2014, indoor) of the loci which deviated from the expected Mendelian inheritance at $P<0.05$ (Tab. III). In each cross, no marker was detected to be significantly distorted simultaneously in both environments. Furthermore, no marker was significantly distorted using a Bonferroni correction. In our study, we revealed a lower or similar level of genetic distortion compared to those reported in other $P$. abies genome studies (without Bonferroni corrections) where segregation distortion affected $5.6 \%$ [32] to $6.6 \%$ [1] of markers. Additionally, when loci inheritance was directly compared between the two maternal environments, we detected differences for $1.3 \%$ (2735) to $5.7 \%$ (1957) of loci per parent at $P<0.05$ (Tab. III) but no locus was detected to be differently inherited in both crosses. When a Bonferroni correction was applied, only one microsatellite locus showed a significantly different inheritance in the male parent of cross I (SpAC03, LG 1; $\chi^{2}=13,1$ d.f., $\left.P<0.05\right)$ while no significant difference was observed in cross II. Our sample size was limited (i.e. about 70 progenies per crossing environment) and our experimental design is certainly effective to detect strong genetic distortion but may be insufficient to detect weak effects. Nevertheless, when compared to many other taxa for which strong genetic distortions have been revealed (e.g. $[15,50]$ ), our results indicate the occurrence of limited genotypic-selection effects during sexual reproduction in the investigated $P$. abies progenies. These results are surprising considering the fact that embryo abortion was much higher in the warm reproductive environment [31].

To test the occurrence of selective effects during diploid reproductive steps (from gamete assortment to seed development) we also looked for genotypic deviations at available co-dominant loci. The analysis revealed deviations in the genotypic class frequencies at one to four loci according to the cross and the crossing environment (at $P<0.05$; data not shown). When a Bonferroni correction was applied, only one deviation at PAAC23 (located on LG 10) was significant in the indoor environment of cross I $\left(\chi^{2}=16.3,3\right.$ d.f., $\left.P<0.05\right)$. However, no effect of maternal environment was found. Thus, this result did not enable us to conclude on the origin of this deviation on the genotypic classes of this locus. 
We can note that the two significant distortions of the present study were revealed in cross I that showed a significant difference in progeny performance according to crossing environments. One hypothesis might be that these two loci are located close to genes affected by selective effects associated to pollen competition during fertilization or to embryo competition during early post-zygotic steps. However, distortion at these loci was not revealed in a third cross $(1957 \times 5994$; data not shown) in which significant difference of progeny performance was also observed between four maternal crossing environments [21]. These results suggest that these loci do not correspond to major distorting factors as revealed in many other taxa (e.g. $[7,50,54])$ and were possibly distorted in cross I just by chance.

In a recent study of climatic adaptation of $P$. abies progenies, Johnsen et al. [22] did not find any phenotypic differences between the progenies that could be related to temperature differences during pre-zygotic stages and fertilization. In contrast, progeny performance appeared to be strongly influenced by the temperature conditions from proembryo to mature seed. In this species, seeds are polyembryonic and they contain a maximum of four genetically different embryos competing for space $[30,31,39]$. Therefore, selection rate during embryo development would not exceed $25 \%$. This theoretical selection intensity of 1.27 [11] is rather low, and possible changes from directional selection during embryo competition cannot entirely account for the large phenotypic differences generally observed among Norway spruce progenies produced in different crossing conditions [22]. In a study on shortleaf pine, Schmidtling and Hipkins [41] used allozymes to test segregation ratio changes between two contrasted reproductive environments. They found significant differences between the two maternal environments. However, the environmental irregularities reflected by allozyme alleles were not well related to the differences in progeny performance induced by the crossing environments. In our study, the progenies produced in warm and cold conditions only exhibit few differences in allele inheritance (i.e. SpAC03 and PAAC23) although they show significantly different phenotypic performances (Tab. I). However we cannot rule out the possibility that genetic selection at a single locus imposes large effects of other genes through pleiotropic interactions, especially if distortions happen in regions where regulatory genes are positioned.

To summarise, we have shown that environmental changes do not induce strong distortions in the segregation of single loci among full sib families during reproduction in P. abies. Of course, our study would need to be repeated to confirm the level of distortion, with an increase of the sample size and possibly replications in time (after several years of growing). The reasons for the difference of phenotypic performance of progenies issued from distinct maternal environments have still to be identified. Imprinting is suspected to play an important role in the rapid responses to environmental changes (e.g. [27]). In order to analyze the trans-generational phenotypic plasticity, further studies should focus on gene expression modifications in $P$. abies progenies following environmental conditions during sexual reproduction. For instance, an analysis of transcription variation at candidate genes could be used to test for parental effects involved in bud set and frost hardiness. In addition, the characterization of progenies obtained in different maternal treatments (e.g. [22]) may bring a transcriptomic validation about the timing of parental effects, which should be mostly influenced by environmental conditions occurring during development of the proembryo to the mature seed [22].

Acknowledgements: This work was supported by the EU program QLK 5-CT-2000-00349, "Importance of regulation mechanisms for the climatic adaptation of tree species (an example of Picea abies)". P.A. Christin and three anonymous reviewers are acknowledged for helpful comments on the manuscript.

\section{REFERENCES}

[1] Acheré V., Faivre Rampant P., Jeandroz S., Besnard G., Markussen T., Aragones A., Fladung M., Ritter E., Favre J.M., A saturated consensus linkage map of Picea abies including AFLP, SSR, STS, 5S rDNA and morphological markers, Theor. Appl. Genet. 108 (2004) 1602-1613.

[2] Agrawal A.A., Herbivory and maternal effects: Mechanisms and consequences of transgenerational induced plant resistance, Ecology 83 (2002) 3408-3415.

[3] Archaux F., Wolters V., Impact of summer drought on forest biodiversity: what do we know? Ann. For. Sci. 63 (2006) 645-652.

[4] Bernasconi G., Ashman T.L., Birkhead T.R., Bishop J.D.D., Grossniklaus U., Kubli E., Marshall D.L., Schmid B., Skogsmyr I., Snook R.R., Taylor D., Till-Bottraud I., Ward P.I., Zeh D.W., Hellriegel B., Evolutionary ecology of the prezygotic stage, Science 303 (2004) 971-975.

[5] Besnard G., Acheré V., Faivre Rampant P., Favre J.M., Jeandroz S., A set of cross-species amplifying microsatellite markers developed from DNA-sequence databanks in Picea (Pinaceae), Mol. Ecol. Notes 3 (2003) 380-383.

[6] Bréda N., Huc R., Granier A., Dreyer E., Temperate forest trees and stands under severe drought: a review of ecophysiological responses, adaptation processes and long-term consequences, Ann. For. Sci. 63. (2006) 625-644.

[7] Buckler E.S. IV, Phelps-Durr T.L., Buckler C.S.K., Dawe R.K., Doebley J.F., Holtsford T.P., Meiotic drive of chromosomal knobs reshaped the maize genome, Genetics 153 (1999) 415-426.

[8] Chagné D., Brown G., Lalanne C., Madur D., Plot D., Neale D., Plomion C., Comparative and QTL mapping between maritime and loblolly pines, Mol. Breed. 12 (2003) 185-195.

[9] Chakraverti A., Lasher L.K., Reefer J.E., A maximum likelihood method for estimating genome length using genetic linkage data, Genetics 128 (1991) 175-182.

[10] Collignon A.M., Van de Sype H., Favre J.M., Geographical variation in random amplified polymorphic DNA and quantitative traits in Norway spruce, Can. J. For. Res. 32 (2002) 266-282.

[11] Falconer D.S., Introduction to quantitative genetics, 3rd ed., Longman Scientific and Technical, John Wiley and Sons, NY, 1989, $438 \mathrm{pp}$.

[12] Galloway L.F., Maternal effects provide phenotypic adaptation to local environmental conditions, New Phytol. 166 (2005) 93-100.

[13] Grattapaglia D., Sederoff R., Genetic linkage maps of Eucalyptus grandis and Eucalyptus urophylla using a pseudo-testcross: mapping strategy and RAPD markers, Genetics 137 (1994) 1121-1137.

[14] Grivet D., Jeandroz S., Favre J.M., Nadl b/c intron polymorphism reveals maternal inheritance of the mitochondrial genome in Picea abies, Theor. Appl. Genet. 99 (1999) 346-349.

[15] Hall M.C., Willis J.H., Transmission ratio distortion in intraspecific hybrids of Mimulus guttatus: implications for genomic divergence, Genetics 170 (2005) 375-386.

[16] Hamrick J.L., Response of forest trees to global environmental changes, For. Ecol. Manage. 197 (2004) 323-335. 
[17] Hodgetts R.B., Aleksiuk M.A., Brown A., Clarke C., Macdonald E., Nadeem S., Khasa D., Development of microsatellite markers for white spruce (Picea glauca) and related species, Theor. Appl. Genet. 102 (2001)1252-1258.

[18] Hulbert S., Ilott T., Legg E.J., Lincoln S., Lander E., Michelmore R., Genetic analysis of the fungus Bremia lactucae, using restriction length polymorphism, Genetics 120 (1988) 947-958.

[19] Jaramillo-Correa J.P., Beaulieu J., Bousquet J., Contrasting evolutionary forces driving population structure at expressed sequence tag polymorphisms, allozymes and quantitative traits in white spruce, Mol. Ecol. 10 (2001) 2729-2740.

[20] Johnsen Ø., Skrøppa T., Junttila O., Dæhlen O.G., Influence of the female flowering environment on autumn frost-hardiness of Picea abies progenies, Theor. Appl. Genet. 92 (1996) 797-802.

[21] Johnsen Ø., Dæhlen O.G., Østreng G., Skrøppa T. Daylength and temperature during seed production interactively affect adaptive performance of Picea abies progenies, New Phytol. 168 (2005) 589-596.

[22] Johnsen Ø., Fossdal C.G., Nagy N., Mølmann J., Dæhlen O.G., Skrøppa T., Climatic adaptation in Picea abies progenies is affected by the temperature during zygotic embryogenesis and seed maturation, Plant Cell Environ. 28 (2005) 1090-1102.

[23] Karhu A., Hurme P., Karjalainen M., Karvonen P., Karkkainen K., Neale D., Savolainen O., Do molecular markers reflect patterns of differentiation in adaptive traits of conifers? Theor Appl Genet 93 (1996) 215-221.

[24] Karl T.R., Trenberth K.E., Modern global climate change, Science 302 (2003) 1719-1723.

[25] Kosambi D.D., The estimation of map distances from recombination values. Ann. Eugen. 12 (1944) 172-175.

[26] Kremer A., Genetic diversity and phenotypic variability of forest trees, Genet. Sel. Evol. 26 (1994) S105-S123.

[27] Lacy E.P., What is an adaptive environmentally induced parental effect? in: Mousseau T.A., Fox C.W. (Eds.), Maternal effects as adaptations, Oxford University Press, Oxford, 1998.

[28] Lenormand T., Dutheil J., Recombination difference between sexes: a role for haploid selection, PLoS Biol. 3 (2005) 396-403.

[29] Maron J.L., Vila M., Bommarco R., Elmendorf S., Beardsley P., Rapid evolution of an invasive plant, Ecol. Monogr. 74 (2004) 261280.

[30] Owens J.N., Blake M.D., Forest tree seed production, Information Report PI-X-53 Petawawa National Forestry Institute, Chalk River, Ontario, 1985, $161 \mathrm{p}$.

[31] Owens J.N., Johnsen Ø., Dæhlen O.G., Skrøppa T., Potential effects of temperature on early reproductive development and progeny performance in Picea abies (L.) Karst., Scand. J. Forest Res. 16 (2001) 221-237.

[32] Paglia G.P., Olivieri A.M., Morgante M., Towards secondgeneration STS (sequence-tagged sites) linkage maps in conifers: a genetic map of Norway spruce (Picea abies K.), Mol. Gen. Genet. 258 (1998) 466-478.

[33] Pardo-Manuel de Villena F., de la Casa-Esperón E., Sapienza C. Natural selection and the function of genome imprinting: beyond the silenced minority, Trends Genet. 16 (2000) 573-579.

[34] Pasonen H.L., Pulkkinen P., Kärkkäinen K., Genotype-environment interactions in pollen competitive ability in an anemophilous tree, Betula pendula Roth., Theor. Appl. Genet. 105 (2002) 465-473.

[35] Perry D.J., Bousquet J., Sequence-tagged-site (STS) markers of arbitrary genes: the utility of black spruce-derived STS primers in other conifers, Theor. Appl. Genet. 97 (1998) 735-743.

[36] Pfeiffer A., Olivieri A.M., Morgante M., Identification and characterization of microsatellites in Norway spruce (Picea abies K.), Genome 40 (1997) 411-419.

[37] Rajora O.P., Rahman M.H., Dayanandan S., Mosseler A., Isolation, characterization, inheritance and linkage of microsatellite DNA markers in white spruce (Picea glauca) and their usefulness in other spruce species, Mol. Gen. Genet. 264 (2001) 871-882.
[38] Rapp R.A., Wendel J.F., Epigenetics and plant evolution, New Phytol. 168 (2005) 81-91.

[39] Sarvas R., Investigations on the flowering and seed crop of Picea abies, Communicationes Instituti Forestalis Fenniae 67 (1968) $1-84$.

[40] Saxe H., Cannell M.G.R., Johnsen Ø., Ryan M.G., Vourlitis G., Tree and forest functioning in response to global warming, New Phytol. 149 (2001) 369-399.

[41] Schmidtling R.C., Hipkins V., The after-effects of reproductive environment in shortleaf pine, Forestry 77 (2004) 287-295.

[42] Schubert R., Sperisen C., Müller-Starck G., La Scala S., Ernst D., Sandermann H., Häger K.P., The cinnamyl alcohol dehydrogenase gene structure in Picea abies (L.) Karst.: genomic sequences, southern hybridization, genetic analysis and phylogenetic relationships, Trees Struct. Funct.12 (1998) 453-463.

[43] Schubert R., Müller-Starck G., Riegel R., Development of ESTPCR markers and monitoring their intrapopulational genetic variation in Picea abies (L.) Karst., Theor. Appl. Genet. 103 (2001) 1223-1231.

[44] Scotti I., Magni F., Fink R., Powell W., Binelli G., Hedley P.E., Microsatellite repeats are not randomly distributed within Norway spruce (Picea abies K.) expressed sequences, Genome 43 (2000) 41-46.

[45] Scotti I., Magni F., Paglia G.P., Morgante M., Trinucleotide microsatellites in Norway spruce (Picea abies): their features and the development of molecular markers, Theor. Appl. Genet. 106 (2002) 46-50.

[46] Scotti I., Paglia G.P., Magni F., Morgante M., Efficient development of dinucleotide microsatellite markers in Norway spruce (Picea abies Karst.) through dot-blot selection, Theor. Appl. Genet. 104 (2002) 1035-1041.

[47] Scotti I., Burelli A., Cattonaro F., Chagné D., Fuller J., Hedley P.E., Jansson G., Lalanne C., Madur D., Neale D., Plomion C., Powell W., Troggio M., Morgante M., Analysis of the distribution of marker classes in a genetic linkage map: a case study in Norway spruce (Picea abies Karst.), Tree Genet. Genomes 1 (2005) 93-102.

[48] Skrøppa T., Kohmann K., Adaptation to local conditions after one generation in Norway spruce, For. Genet. 4 (1997) 165-180.

[49] Sokal R.R., Rohlf F.J., Biometry, 4th ed., WH Freeman, New York, 1998.

[50] Taylor D.R., Ingvarsson P.K., Common features of segregation distortion in plants and animals, Genetica 117 (2003) 27-35.

[51] Temesgen B., Brown G.R., Harry D.E., Kinlaw C.S., Sewell M.M., Neale D.B., Genetic mapping of expressed sequence tag polymorphism (ESTP) markers in loblolly pine (Pinus taeda L.), Theor. Appl. Genet. 102 (2001) 664-675.

[52] Trontin J.F., Grandemange C., Favre J.M., Two highly divergent 5S rDNA unit size classes occur in composite tandem array in European larch (Larix decidua Mill.) and Japanese larch (Larix kaempferi (Lamb.) Carr.), Genome 42 (1999) 837-848.

[53] Van Ooijen J.W., Voorrips R.E., JoinMap 3.0, Software for the calculation of genetic linkage maps, Plant Research International, Wageningen, The Netherlands, 2001, and website: http://www.plant.wageningen-ur.nl.

[54] Vogl C., Xu S., Multiple point mapping of viability and segregation distorting loci using molecular marker, Genetics 155 (2000) 14391447.

[55] Webber J., Ott P., Owens J., Binder W., Elevated temperature during reproductive devlopment affects traits and progeny performance in Picea glauca $\times$ engelmannii complex, Tree Physiol. 25 (2005) 1219-1227.

[56] Young W.P., Schupp J.M., Keim P.D.N.A., methylation and AFLP distribution in the soybean genome, Theor. Appl. Genet. 99 (1999) 785-790. 